\title{
Modeling codling moth (Lepidoptera: Tortricidae) phenology and predicting egg hatch in apple orchards of the Maule Region, Chile
}

\author{
Wilson Barros-Parada ${ }^{1}$, Alan L. Knight ${ }^{2}$, and Eduardo Fuentes-Contreras ${ }^{1^{*}}$
}

Studies were conducted in the Maule Region to characterize the phenology of the codling moth, Cydia pomonella (L.) The Predictive Extension Timing Estimator (PETE) and a logistic phenological model were validated with eight data sets of cumulative moth catches in sex pheromone $(\mathrm{PH})$ and kairomone-baited traps and the cumulative occurrence of fruit injuries from apple (Malus domestica Borkh.) orchards during the 2009-2011 seasons. Second, the start of egg hatch was predicted from the first sustained male and female moth catches (biofix) in traps baited with pear ester (PE), PE+acetic acid (AA), $\mathrm{PE}+\mathrm{PH}$, and $\mathrm{PH}$ alone. Both phenological models fit data well except that the logistic provided a better fit than the PETE model of the phenology of egg hatch of the codling moth in the first generation, with a difference of $11 \mathrm{~d}$ between models in the prediction of $50 \%$ egg hatch. No significant difference was found between biofix dates established for males using either $\mathrm{PH}$ or $\mathrm{PE}+\mathrm{PH}$ lures or for the biofix date based on female catches with $\mathrm{PE}+\mathrm{AA}$ or $\mathrm{PH}+\mathrm{PE}$. The biofix established with the sustained female catch occurred nearly $11 \mathrm{~d}$ later than the male-based biofix. The use of a female biofix provided on average a 4-d improvement in the prediction of first egg hatch compared with the traditional use of a male biofix, but this difference was not significant. The use of PE+AA lures increased the proportion of cases when a female-based biofix could be established compared with the use of the PH+PE lure.

Key words: Biofix, Cydia pomonella, degree days, codlemone, Malus domestica, pear ester.

\section{INTRODUCTION}

Phenological models have been important tools used to improve the management of codling moth, Cydia pomonella (L.) (Lepidoptera: Tortricidae) in many apple producing areas worldwide (Tomkins et al., 1987; Knight and Croft, 1991; Blago, 1992; Ahmad et al., 1995; Boivin et al., 2005; Samietz et al., 2007; Knight, 2007; Jones et al., 2008; 2010; 2013). The Predictive Extension Timing Estimator (PETE) model was the first widely-adopted phenological model developed for codling moth in the USA, and is based on a time-varying distributed delay algorithm (Welch et al., 1978). The validation of PETE codling moth model was performed successfully with data of accumulated male adult catches in sex pheromonetraps $(\mathrm{PH})$ and egg-hatching in relation to degree days (DD) (Riedl et al., 1976). Subsequently, PETE models were implemented in many apple producing states in the USA (Jorgensen et al., 1979; Welch et al., 1981; Brunner et al., 1982; Croft and Knight, 1983; Pitcairn et al., 1992; Beers and Brunner, 1992). Efforts to validate

\footnotetext{
${ }^{1}$ Universidad de Talca, Facultad de Ciencias Agrarias, Casilla 747, Talca, Chile. *Corresponding author (efuentes@utalca.cl).

${ }^{2}$ United States Department of Agriculture, Agricultural Research Service (USDA-ARS), 5230 Konnowac Pass Road, Wapato, WA 98951, USA.

Received: 4 February 2014.

Accepted: 2 October 2014.

doi: $10.4067 /$ S0718-58392015000100008
}

PETE on apple pests in Chile started in the 1980's (Croft and Knight, 1983; Vial, 1987), but growers' interest in its implementation was low due to their reliance on repeated calendar-based insecticide sprays in order to meet the strong quarantine restrictions imposed by export markets (González, 2003). Currently, the PETE codling moth model is available in Chile on a web-based service (http:// www.agroclima.cl) to farmers associated with "Fundación para el Desarrollo Frutícola" (FDF).

A new phenology model was developed for codling moth in Washington State (USA), because of the reported poor fit of the PETE model that many growers observed in this region once sex pheromones began to be adopted for mating disruption and insecticide spray programs became more limited (Knight, 2007). The cumulative curves for both adult emergence and egg hatch based on male catches in sex pheromone-traps and newly injured fruits were fit to logistic equations for both generations of codling moth, and the new model predicted a delay of 100 degree-days (DD) from the PETE model for $50 \%$ egg hatch in the first generation (Knight, 2007). The potential impact of this difference between models on the effectiveness of insecticide programs targeting eggs and neonate larvae of the codling moth was shown conceptually to be an important concern for effective insecticide-based management of this pest. This concern is heightened today as growers must rely on the use of selective insecticides which often have shorter residual activity than the previous broad spectrum insecticides 
(Brunner et al., 2005; Jones et al., 2010). Therefore, phenology models available to aid management decisions need to be accurate at a temporal scale consistent with spray timing decisions to reduce the probability of control failures (Knight, 2007).

Recognition by apple growers in Chile that the development and implementation of accurate phenology models for codling moth is important has increased (González, 2003). Here, apple production is primarily export-driven and due to severe quarantine restrictions for codling moth-injured fruits growers' reliance on insecticide use is high. Efforts to minimize residues on fruit and improve the safety of workers and avoid disturbing the population dynamics of secondary pests, such as San José scale, Diaspidiotus perniciosus (Comstock), and wooly apple aphid, Eriosoma lanigerum (Hausmann), are key factors affecting fruit production. Development of a more accurate predictive phenology model should allow growers to further reduce their use of insecticides and these associated negative impacts.

Identification of $(E, Z)$-2,4-ethyl-decadienoate (pear ester, PE) as a potent attractant for both sexes of codling moth (Light et al., 2001), as well as the use of acetic acid (AA) as a synergist to increase the catch of both sexes (Landolt et al., 2007), has allowed the development of new traps and lures for codling moth monitoring (Knight, 2010a; 2010b; 2010c; Barros-Parada et al., 2013). These new technologies provide potential alternatives for the definition of more accurate biological events to start the accumulation of DD in phenological models (Knight and Light, 2005a; 2005b).

Biofix was originally defined as "the first male moth or moths in the traps baited with the sex pheromone, (E,E)-8,10-dodecadien-1-ol (PH), with no significant interruption in catches thereafter" (Riedl et al., 1976). This definition of a sustained biofix has been further adjusted with the occurrence of suitable dusk temperatures for moth sexual activity ( $>15.6{ }^{\circ} \mathrm{C}$ ) (Pickel et al., 1986; Blago, 1992) or suitable maximum daily temperatures (> $21.1^{\circ} \mathrm{C}$ ) (Pitcairn et al., 1990). More recently, Knight and Light (2005a) using traps baited with PE re-defined the biofix for male, female or any sustained catches with an adjustment for maximum daily temperature.

Herein, we report the results from studies aimed to i) statistically validate the codling moth PETE (Brunner et al., 1982) and logistic models (Knight, 2007) for adult male catches and egg hatch in the Maule Region of central Chile; and ii) compare the establishment of a biofix based on sustained codling moth male and/or female catches in traps baited with $\mathrm{PE}+\mathrm{AA}, \mathrm{PE}+\mathrm{PH}$, or $\mathrm{PH}$.

\section{MATERIALS AND METHODS}

\section{Field studies}

Five abandoned apple (Malus domestica Borkh.) orchards in the Maule Region, Chile, were monitored during the 2009-2010 and 2010-2011 seasons. The Pencahue

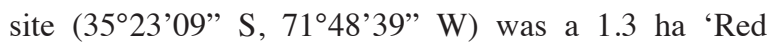
King Oregon', 'Royal Gala', and 'Fuji' orchard; the

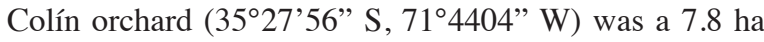
mixed block of 'Red Chief', 'Royal Gala' and 'Granny Smith', and the Talca site (35'27'26' S, 71'36'33" W) was a 1-ha mixed block of 'Fuji' and 'Royal Gala'. All three of these sites were monitored in both seasons. The Villa Alegre orchard $\left(35^{\circ} 01^{\prime} 12^{\prime \prime} \mathrm{S}, 71^{\circ} 14^{\prime} 26^{\prime \prime} \mathrm{W}\right)$ was a 5.8 ha mixed block of 'Granny Smith' and 'Royal Gala' monitored only in 2009-2010. The Rauco orchard

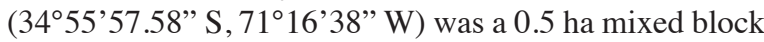
of 'Red King Oregon', 'Granny Smith', and 'Royal Gala' monitored only in 2010-2011. The mean tree height in orchards varied from 1.8 to $5.4 \mathrm{~m}$, and the tree densities were between 666-1250 trees ha ${ }^{-1}$. All orchards had been abandoned for $>8 \mathrm{yr}$, and no insecticide sprays or mating disruption technologies were used in any of the sites during the 2-yr study.

Trees (3-20 per site) with a full fruit load were randomly selected in each orchard at the beginning of the season following bloom to provide an estimated population of 2000-3500 fruits per site. During both seasons, trees selected at each site were sampled once a week. Two technicians examined all fruits on designated trees using ladders on each date. Sampling efforts on each date ranged from 1 to $2 \mathrm{~h}$ per orchard depending on the number of fruits checked, number of fruits removed, and tree size. Degree days (DD) were calculated with a simple sine wave function using $10^{\circ} \mathrm{C}$ and $31.1^{\circ} \mathrm{C}$ as temperature thresholds with a horizontal cutoff (Baskerville and Emin, 1969). The accumulated mean DD (SE) between sampling dates was 59.2 (1.3) for the first generation and 95.4 (3.0) for the second generation of codling moth. A variable proportion of damaged fruit evaluated in all orchards had multiple injuries. Data on the total number of injuries were recorded, instead of the number of injured fruits. On each sampling date damaged fruits were removed to avoid counting them on the next evaluation date. The proportion of fruits left on sampled trees, after removal of fruits with injuries, by the end of the season was 0.05 0.8 in all sites, except for the first and second generation at Colín during 2009-2010, where little damage occurred and these data were not included in the study. Also, in the Pencahue orchard during 2009-2010 the proportion of fruit injury was $>0.95$ by mid-season, and data for the second generation were not included in the analyses.

Male and female codling moth were monitored in each orchard with five trap-lure combinations during the 20092010 season: i) clear delta-pear ester (PE) (Pherocon DA, Trécé Inc., Adair, Oklahoma, USA) + acetic acid (AA), ii) clear round-PE+AA, iii) orange delta-PE+ sex pheromone (PH) (Pherocon CM-DA Combo, Trécé Inc., Salinas, California, USA), iv) white delta-PE+ $\mathrm{PH}$, and v) white delta-PH (Pherocon CM L2, Trécé Inc., Salinas). Clear delta and round delta-PE+AA as well as orange delta and white 
delta-PE+PH showed similar catches of codling moth, and therefore only one of each was used in the following season. During the 2010-2011 season three trap-lure combinations were used: i) clear delta-PE+AA, ii) orange delta-PE+PH, and iii) white delta-PH. The AA lure was prepared with 6 $\mathrm{mL}$ glacial acetic acid (99\%) (Sigma-Aldrich, St. Louis, Missouri, USA) added to a $8.0 \mathrm{~mL}$ polyethylene vial (NalgNunc International, Rochester, New York, USA) with a 3.0 $\mathrm{mm}$ hole in the screw cap. A $10 \mathrm{~g}$ cotton ball was put into each vial as described by Barros-Parada et al. (2013). Clear delta and round traps were made of plastic film as described by Knight (2010b) and Barros-Parada et al. (2013). Traps were attached to poles in the upper third of the tree canopy (approx. $3 \mathrm{~m}$ high) according to the protocol described by Knight et al. (2006). An array of traps was placed with an N-S orientation with traps spaced $30-50 \mathrm{~m}$ apart and $\geq$ $10 \mathrm{~m}$ from the edge of the orchard. Lures were replaced every $8 \mathrm{wk}$ and the sticky liners when needed. Traps were checked two or three times per week and rotated within the array on each sampling date. Moths were removed from traps on each date and sexed in the field (Riedl et al., 1976). Daily temperature was recorded with a data-logger (Hobo, Bourne, Massachusetts, USA) located in the tree canopy at each sampling site. Total male trap catches and egg hatch for each flight and season were compared with repeated measures ANOVA.

\section{Validation of phenological models}

Accumulated male moth catches in sex pheromone-baited traps as a function of DD accumulations during the season were used to calculate the proportion of the flight cycle for each generation of codling moth. Since no significant differences in the male accumulated proportion of catches between trap-lure combinations ( $\mathrm{PH}$ and $\mathrm{PE}+\mathrm{PH}$ ) were found, the pooled catches were used to evaluate the fit of the models.

The biofix in each orchard-year was established from sustained male moth catch. The moth catch that occurred on the biofix date was assigned the total DD accumulated on the day the trap was checked. The fruit damage was used as an estimation of egg hatch, assuming the occurrence of fruit injury $1 \mathrm{~d}$ after egg hatching as suggested by Knight (2007). Therefore, registered DD for each orchard in the day before the detection of fruit damage were also accumulated. The duration of codling moth flight and the egg hatch period for the first and second generation were set as 444 and 567 and 1044 and 1189 DD after biofix, respectively (Brunner et al., 1982). This approach was used because it is not possible to clearly distinguish between the first and second generations of codling moth due to some overlapping development.

The statistical validation of these data fit to the logistic model (WA logistic) developed for Washington by Knight (2007) and a logistic version of the PETE model (Brunner et al., 1982) was performed. The PETE logistic model was developed from the tabular data of the cumulative moth flight and egg hatch as a function of DD available in Brunner et al. (1982). The fit between observed and predicted values was compared with the coefficient of determination $\left(\mathrm{R}^{2}\right)$, root mean square error (RMSE), and mean absolute error (MAE) defined by Mayer and Butler (1993). Finally, the differences in DD between model predictions for $10 \%, 50 \%$, and $90 \%$ completion of adult male flight and egg hatch were calculated.

\section{Biofix determination}

Several types of trap catch data from each orchard were used to establish a biofix for male and female adult emergence: i) sustained male catch in traps baited with $\mathrm{PH}$, $\mathrm{PE}+\mathrm{AA}$ or $\mathrm{PE}+\mathrm{PH}$ lures; and ii) sustained female catch in traps baited with $\mathrm{PE}+\mathrm{PH}$ or $\mathrm{PE}+\mathrm{AA}$ lures. Data from different types of traps were pooled in these determinations. A strict definition of a biofix was adhered to as the date of sustained catch in which at least two consecutive days with maximum temperatures above $21.1{ }^{\circ} \mathrm{C}$ occurred between trap checks, with the following modifications from the definition described by Knight and Light (2005a). First, sustained catch in this study was defined as the date when two consecutive trap checks caught at least one individual moth, instead of an average catch of one moth per trap. Second, sustained catch was established at the start of the period of the second consecutive individual catch, instead of the start of the period from the first of the consecutive catches above one moth per trap. The Julian date (JD) of these defined biofix's was used to compare trap-lure treatments. The cumulated DD from the observed to the expected occurrence of egg hatch were estimated using the backtracking data from Knight and Light (2005a). Observed egg hatch was obtained from fruit damage evaluations, based on the assumption that egg hatch started $1 \mathrm{~d}$ after the previous sampling date without damage detection. The mean and (SE) DD between fruit damage detection and observed egg hatch was 29.6 (4.4) DD. Differences between biofix as JD, and in the observed and expected dates and DD totals for egg hatch were analyzed with a non-parametric Kruskal-Wallis test.

\section{RESULTS}

\section{Seasonal male catches and egg hatch}

The cumulative catches of codling moth males in the traps were not significantly different between generations $\left(\mathrm{F}_{1,6}\right.$ $=0.04, P=0.85)$, seasons $\left(\mathrm{F}_{1,6}=1.94, P=0.21\right)$ or with the interaction of these two factors $\left(\mathrm{F}_{1,6}=0.83, P=0.40\right)$. The numbers of fruit injuries was significantly lower in the first than the second year $\left(\mathrm{F}_{1,4}=9.93, P<0.05\right)$, but not between generations $\left(\mathrm{F}_{1,4}=1.43, P=0.30\right.$, NS) nor was the interaction Year $\times$ Generation significant $\left(\mathrm{F}_{1,4}=\right.$ $3.07, P=0.15)$.

\section{Model validation}

The logistic and the PETE logistic fit models showed similar $\mathrm{R}^{2}$, MAE, and RMSE for both adult male 
emergence periods (Table 1). However, the WA logistic model for the first generation egg hatch had a higher $\mathrm{R}^{2}$ and lower MAE and RMSE than those obtained for the PETE logistic model (Table 1). In contrast, both models had similar $\mathrm{R}^{2}$, MAE, and RMSE values for the second generation egg hatch period (Table 1).

The difference between the WA logistic and the PETE logistic model of adult male emergence was 22 DD and -4 DD for $50 \%$ of the first and second flight, which correspond approximately to $3 \mathrm{~d}$ and less than $1 \mathrm{~d}$ for the first and second flight, respectively (Table 2). On the contrary, for the first egg hatch period the $50 \%$ egg hatch showed a difference of 81 DD between models (Table 2). This difference was only 7 DD for the second egg hatch period (Table 2). Since mean orchard temperatures were lower in spring than in summer, the difference between models in DD has a stronger effect in calendar days for the first (11 d) than for the second (1 d) egg hatch period. Such differences resulted in a more accurate prediction of the first egg-hatch by the WA logistic than by PETE logistic model, which showed -50 DD and -130 DD difference with the mean egg-hatch detected in the field, respectively (Table 2 ).

Table 1. Values of statistical validation criteria used to compare the WA logistic and the PETE logistic model for codling moth phenology during the first and generation in apple orchards during 2009-2011 from the Maule Region, Chile.

\begin{tabular}{lccccc}
\hline \multirow{2}{*}{ Event } & Model & $\begin{array}{c}\text { Number of } \\
\text { data points }\end{array}$ & $\mathrm{R}^{2}$ & RMSE & MAE \\
\hline $1^{\text {st }}$ Flight & WA-Logistic & 571 & 0.79 & 0.21 & 0.15 \\
& PETE-Logistic & 571 & 0.83 & 0.18 & 0.13 \\
$2^{\text {nd }}$ Flight & WA-Logistic & 438 & 0.78 & 0.19 & 0.13 \\
& PETE-Logistic & 438 & 0.78 & 0.18 & 0.13 \\
$1^{\text {st }}$ Egg hatch & WA-Logistic & 114 & 0.94 & 0.11 & 0.06 \\
& PETE-Logistic & 114 & 0.78 & 0.27 & 0.18 \\
$2^{\text {nd }}$ Egg hatch & WA-Logistic & 69 & 0.90 & 0.11 & 0.09 \\
& PETE-Logistic & 69 & 0.89 & 0.13 & 0.09
\end{tabular}

$\mathrm{R}^{2}$ : Coefficient of determination, higher values denote a better data fit. All regressions were significant $P<0.05$; RMSE: root mean square error, lower values denote a better fit of data; MAE: mean absolute error, lower values denote a better fit of data.

\section{Biofix determination}

The timing of first sustained female catch in traps baited with $\mathrm{PE}+\mathrm{PH}$ and $\mathrm{PE}+\mathrm{AA}$ lures were not significantly different, but were significantly later compared to the timing of first sustained male catches with $\mathrm{PH}$ or $\mathrm{PE}+\mathrm{PH}$ lures, but not from PE+AA lures (Table 3). The sustained catch of females was not established in four out of eight orchards with $\mathrm{PE}+\mathrm{PH}$ lures, and in only one out of eight orchards for PE+AA lures. The biofix date for first sustained male catch with $\mathrm{PH}$ or $\mathrm{PE}+\mathrm{PH}$ lures were not significantly different (Table 3). Differences in the gap between observed and expected egg hatch among the different biofix types ranged over $4.5 \mathrm{~d}$ and $30 \mathrm{DD}$, but were not significant (Table 3).

\section{DISCUSSION}

Codling moth management in Chile is characterized as an intensive program of repeated insecticide sprays timed to maintain effective residues which protect the fruit from larval injuries (González, 2003). Failure to protect the fruit, even with a low proportion of larval infestation, produces the quarantine rejection of the pome fruit exports to the most profitable markets (e.g. Taiwan). When growers rely primarily on a number of broad spectrum insecticides with long residual effects (e.g. organophosphate, OP) the accuracy and precision of codling moth phenological predictions were not a major concern. However, with the replacement of OP with selective and shorter residual effect insecticides (Brunner et al., 2005; Jones et al., 2010) the improvements of phenological estimations for codling moth control are more relevant (Knight, 2007).

Our work found that the logistic model developed by Knight (2007) and the widely used PETE model (Brunner et al., 1982) were both able to predict the phenology of codling moth male flight in Maule Region, Chile. However, the logistic model appeared to predict 50\% egg hatch for the first codling moth generation better than the PETE model, with a difference of $80 \mathrm{DD}$ or about $11 \mathrm{~d}$ between

Table 2. Observed and predicted degree-days (DD) values of the WA logistic and the PETE logistic models for codling moth flight and egg hatch in apple orchards during 2009-2011 seasons from the Maule Region, Chile.

\begin{tabular}{|c|c|c|c|c|c|c|}
\hline \multirow[b]{2}{*}{$\begin{array}{l}\text { Event (\% } \\
\text { completion) }\end{array}$} & \multicolumn{3}{|c|}{ DD value for event } & \multicolumn{3}{|c|}{ Difference between } \\
\hline & $\begin{array}{l}\text { Field data mean } \\
\text { (SE) }\end{array}$ & $\begin{array}{l}\text { WA- } \\
\text { Logistic }\end{array}$ & $\begin{array}{l}\text { PETE- } \\
\text { Logistic }\end{array}$ & $\begin{array}{l}\text { WA-Logistic and } \\
\text { field data }\end{array}$ & $\begin{array}{l}\text { PETE-Logistic } \\
\text { and field data }\end{array}$ & $\begin{array}{l}\text { Logistic } \\
\text { models }\end{array}$ \\
\hline \multicolumn{7}{|l|}{$1^{\text {st }}$ Flight } \\
\hline 10 & $54(28)$ & 93 & 27 & 39 & -27 & 66 \\
\hline 50 & $164(72)$ & 170 & 148 & 6 & -16 & 22 \\
\hline 90 & $362(50)$ & 289 & 271 & -73 & -91 & 18 \\
\hline \multicolumn{7}{|l|}{$2^{\text {nd }}$ Flight } \\
\hline 10 & $621(103)$ & 595 & 592 & -26 & 29 & 3 \\
\hline 50 & $812(74)$ & 748 & 752 & -64 & -60 & -4 \\
\hline 90 & $975(48)$ & 901 & 911 & -74 & -64 & -10 \\
\hline \multicolumn{7}{|l|}{$1^{\text {st }}$ Egg hatch } \\
\hline 10 & $293(36)$ & 257 & 173 & -36 & -120 & 84 \\
\hline 50 & $413(28)$ & 364 & 283 & -49 & -130 & 81 \\
\hline 90 & $520(51)$ & 472 & 393 & -48 & -127 & 79 \\
\hline \multicolumn{7}{|l|}{$2^{\text {nd }}$ Egg hatch } \\
\hline 10 & $677(53)$ & 709 & 725 & 32 & 48 & -16 \\
\hline 50 & $966(81)$ & 892 & 885 & -74 & -81 & 7 \\
\hline 90 & $1120(56)$ & 1074 & 1045 & -46 & -75 & 29 \\
\hline
\end{tabular}


Table 3. Mean (SE) Julian date of male or female codling moth biofix established with pear ester plus acetic acid (PE+AA), pear ester plus sex pheromone (PE+PH), and sex pheromone (PH) lures, and the differences expressed as Julian dates and degree-days (DD) between predicted and observed first egg hatch in apple orchards during 2009-2011 seasons from Maule Region, Chile.

\begin{tabular}{|c|c|c|c|c|c|c|}
\hline \multirow[b]{3}{*}{ Lure } & & & \multicolumn{4}{|c|}{ Difference between observed and expected egg hatch } \\
\hline & \multicolumn{2}{|c|}{ Julian date of biofix ${ }^{a}$} & \multicolumn{2}{|c|}{ Julian date } & \multicolumn{2}{|c|}{ DD } \\
\hline & Male $^{b}$ & Female $^{b}$ & Male & Female & Male & Female \\
\hline $\mathrm{PE}+\mathrm{AA}$ & $284.8(3.9) \mathrm{a}$ & $285.3(2.7) \mathrm{a}$ & $8.3(2.8)$ & $6.3(2.3)$ & $54.5(16.4)$ & $35.9(11.2)$ \\
\hline $\mathrm{PH}+\mathrm{PE}$ & $275.5(2.3) \mathrm{b}$ & $287.3(2.2) \mathrm{a}$ & $10.4(2.3)$ & $6.8(3.3)$ & $61.9(11.5)$ & $54.4(15.6)$ \\
\hline \multirow[t]{2}{*}{$\mathrm{PH}$} & $274.8(1.9) \mathrm{b}$ & - & $10.8(2.5)$ & - & $66.0(14.3)$ & - \\
\hline & \multicolumn{2}{|c|}{$\begin{array}{c}\mathrm{H}_{(4,35)}=16.0 \\
P<0.05\end{array}$} & \multicolumn{2}{|c|}{$\begin{array}{c}\mathrm{H}_{(4,35)}=3.5 \\
P=0.49\end{array}$} & \multicolumn{2}{|c|}{$\begin{array}{c}\mathrm{H}_{(4,35)}=3.2 \\
P=0.52\end{array}$} \\
\hline
\end{tabular}

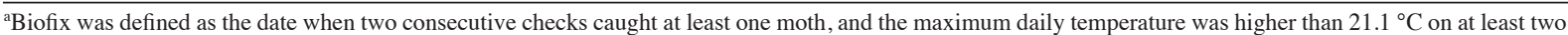
consecutive days from the previous trap check date.

${ }^{b}$ Different letters show significant differences according to Kruskal-Wallis multiple comparison test.

them. This difference is likely significant and suggests that current timing of growers' insecticide sprays in Chile may not be optimal (Knight, 2007). The similarity of our findings in Chile and Washington (Knight, 2007) suggests that albeit differences in latitude, altitude, apple varieties, training systems, insecticide sprays, etc., the phenology of the codling moth can be predicted successfully using a logistic phenological model in different regions. However, some seasons temperature during winter allows insect activity in central Chile, and therefore model predictions should be followed in addition to trap use and direct observation of the pest phenology.

Knight (2007) suggested that this observed difference in the phenology of codling moth that has been reported over a 30-yr period could be associated with OP resistance. Previous studies had found an increase in codling moth development time and a subsequent phenological delay of insecticide resistant individuals, which has been suggested as a pleiotropic cost of insecticide resistance (Boivin et al., 2005). Detectable levels of insecticide resistance have been reported in codling moth from both Washington (Varela et al., 1993; Knight, 2010d) and Maule (Reyes et al., 2004; Fuentes-Contreras et al., 2007), which may support the similar phenological differences found in Washington and Chile compared with Michigan in the 1970's. However, the similar experimental designs and several relevant differences with the methods used by Riedl et al. (1976) may also account for these different models.

New trap designs and lures (Landolt et al., 2007; Knight, 2010a; 2010b; 2010c; Barros-Parada et al., 2013) are another potential source of improved data for phenology modeling of the codling moth. The catch of female adults in the traps lured with $\mathrm{PE}+\mathrm{AA}$, although higher than in orange delta traps with $\mathrm{PE}+\mathrm{PH}$ (combo) lures (Barros-Parada et al., 2013), was not large enough to allow the development of a phenological model for female adults in our current study. Traps with PE+PH combo lures are known to catch a low proportion of female codling moth in relation with PE+AA baited traps (Knight, 2010a; 2010b; 2010c; Barros-Parada et al., 2013). However, we found that a female-based biofix using $\mathrm{PE}+\mathrm{AA}$ or $\mathrm{PE}+\mathrm{PH}$ lures occurred significantly later than a male-based biofix. Furthermore, $\mathrm{PE}+\mathrm{AA}$ lures seem to be more reliable than
$\mathrm{PE}+\mathrm{PH}$ lures to establish a female-based biofix due to their higher propensity to catch females (Knight, 2010a; 2010b; 2010c; Barros-Parada et al., 2013). Because, the male biofix estimated with $\mathrm{PE}+\mathrm{AA}$ in relation with $\mathrm{PE}+\mathrm{PH}$ and $\mathrm{PH}$ lures was not significantly different, the PE+AA lure can be used to estimate both male and female biofix. The use of a female-based biofix showed a trend to predict more closely the start of egg hatch in either JD or DD units compared with the standard sustained male catch in $\mathrm{PH}$ or $\mathrm{PE}+\mathrm{PH}$ traps, but this difference was not large enough to be significant in our study. On the contrary, this difference was significant in an earlier study for males (Knight and Light, 2005a). Likely, the wide sampling interval used in or study (60 DD in spring and 95 DD in summer) limited our ability to more closely differentiate the timing of first egg hatch in relation with shorter sampling intervals achieved by Knight (2007) (36.6-83.0 DD).

\section{CONCLUSIONS}

The Predictive Extension Timing Estimator (PETE) and logistic models for codling moth phenology adequately estimated the adult male flight periods of the codling moth in the Maule Region, Chile. However, the logistic model showed a better estimation of the first egg-hatch period than the PETE model. This difference between models can reach up to $10 \mathrm{~d}$ and could produce a mismatch between the first insecticide spray and egg-hatch of neonate larvae that can damage the fruits. Biofix from sustained catch of females with pear ester and sex pheromone $(\mathrm{PE}+\mathrm{PH})$ and (PE+ acetic acid [AA]) lures was significantly delayed in relation with the standard biofix obtained from sustained catch of males in $\mathrm{PH}$ or $\mathrm{PE}+\mathrm{PH}$ lures. $\mathrm{PE}+\mathrm{AA}$ baited traps were more reliable than $\mathrm{PE}+\mathrm{PH}$ to establish a female biofix, and could be used in combination with a logistic phenological model that should be developed for female codling moth.

\section{ACKNOWLEDGEMENTS}

This work was funded by FONDECYT grant 1071029 to EFC, and Millenium Nucleus (Molecular Ecology and Evolutionary Applications in the Agroecosystem) grant NC 120027 


\section{LITERATURE CITED}

Ahmad, T.R., M. Ali, and B. Hamad. 1995. Using degree-days model to determine the optimum spray timing for the codling moth Cydia pomonella (L.) (Lep., Olethreutidae). Journal of Applied Entomology 119:143-144.

Barros-Parada, W., A.L. Knight, E. Basoalto, and E. FuentesContreras. 2013. Evaluation of traps and lures for codling moth (Lepidoptera: Tortricidae) in apple orchards. Ciencia e Investigación Agraria 39:307-315.

Baskerville, G.L., and P. Emin. 1969. Rapid estimation of heat accumulation from maximum and minimum temperatures. Ecology 50:515-517.

Beers, E.H., and J.F. Brunner. 1992. Implementation of the codling moth phenology model on apples in Washington State, USA. Acta Phytopathologica et Entomologica Hungarica 27:97-102.

Blago, N. 1992. "BUGOFF 2 G" The adaptation of a Californian model for the codling moth to the central European condition. Acta Phytopathologica et Entomologica Hungarica 27:119-125.

Boivin, T., J. Chadoeuf, J.-C. Bouvier, D. Beslay, and B. Sauphanor. 2005. Modelling the interactions between phenology and insecticide resistance genes in the codling moth Cydia pomonella. Pest Management Science 61:53-67.

Brunner, J.F., S.C. Hoyt, and M.A. Wright. 1982. Codling moth control a new tool for timing sprays. Washington State University, Pullman, Washington, USA.

Brunner, J.F., E. Beers, J. Dunley, and M. Doerr. 2005. Role of neonicotinyl insecticides in Washington apple integrated pest management. Part I. Control of lepidopteran pest. Journal of Insect Science 5:14.

Croft, B.A., and A.L. Knight. 1983. Evaluation of the PETE phenology modeling system for integrated pest management of deciduous tree fruit species. Bulletin of the Entomological Society of America 29:37-42.

Fuentes-Contreras, E., M. Reyes, W. Barros, and B. Sauphanor. 2007. Evaluation of azinphosmethyl resistance and activity of detoxifying enzymes in codling moth (Lepidoptera: Tortricidae) from central Chile. Journal of Economic Entomology 100:551-556.

González, R.H. 2003. Las polillas de la fruta en Chile (Lepidoptera: Tortricidae, Pyralidae). Universidad de Chile, Santiago, Chile.

Jones, V.P., J.F. Brunner, G.G. Grove, B. Petit, G.V. Tangren, and W.E. Jones. 2010. A web-based decision support system to enhance IPM programs in Washington tree fruit. Pest Management Science 66:587-595

Jones, V.P., M. Doerr, and J.F. Brunner. 2008. Is biofix necessary for predicting codling moth (Lepidoptera: Tortricidae) emergence in Washington State apple orchards? Journal of Economic Entomology 101:1651-1657.

Jones, V.P., R. Hilton, J.F. Brunner, W.J. Bentley, D.G. Alston, B. Barrett, et al. 2013. Predicting the emergence of the codling moth, Cydia pomonella (Lepidoptera: Tortricidae), on a degree-day scale in North America. Pest Management Science 69:1393-1398.

Jorgensen, C.D., M.E. Martinsen, and L.J. Westover. 1979. Validating Michigan State University's codling moth model (MOTHMDL) in an arid environment: a test in Utah. Great Lakes Entomologist 12:203-212.

Knight, A.L. 2007. Adjusting the phenology model of codling moth (Lepidoptera: Tortricidae) in Washington state apple orchards. Environmental Entomology 36:1485-1493.

Knight, A.L. 2010a. Effect of sex pheromone and kairomone lures on catches of codling moth. Journal of the Entomological Society of British Columbia 107:67-74.

Knight, A.L. 2010b. Increased catch of female codling moth (Lepidoptera: Tortricidae) in kairomone-baited clear delta traps. Environmental Entomology 39:583-590.

Knight, A.L. 2010c. Improved monitoring of female codling moth (Lepidoptera: Tortricidae) with pear ester plus acetic acid in sex pheromone-treated orchards. Environmental Entomology 39:1283-1290.
Knight, A.L. 2010d. Cross-resistance between azinphos-methyl and acetamiprid in populations of codling moth, Cydia pomonella (L.) (Lepidoptera: Tortricidae), from Washington State. Pest Management Science 66:865-874.

Knight, A.L., and B.A. Croft. 1991. Modeling and protection technology. p. 301-311. In Van der Geest L.P.S. and H. Evenhuis (eds.) Tortricid pests: Their biology, natural enemies and control. Elsevier Science Publishers, Amsterdam, The Netherlands.

Knight, A.L., R. Hilton, P. Van Buskirk, and D.M. Light. 2006. Using pear ester to monitor codling moth in sex pheromone treated orchards. Oregon State University Extension Service, Medford, Oregon, USA.

Knight, A.L., and D.M. Light. 2005a. Timing of egg hatch by earlyseason codling moth (Lepidoptera: Tortricidae) predicted by moth catch in pear ester- and codlemone-baited traps. Canadian Entomologist 137:728-738.

Knight, A.L., and D.M. Light. 2005b. Developing action thresholds for codling moth (Lepidoptera: Tortricidae) with pear ester- and codlemone-baited traps in apple orchards treated with sex pheromone mating disruption. Canadian Entomologist 137:739-747.

Landolt, P.J., D.M. Suckling, and G.J.R. Judd. 2007. Positive interaction of a feeding attractant and a host kairomone for trapping the codling moth, Cydia pomonella. Journal of Chemical Ecology 33:2236-2244.

Light, D.M., A.L. Knight, C.A. Henrick, D. Rajapaska, B. Lingren J.C. Dickens, et al. 2001. A pear-derived kairomone with pheromonal potency that attracts male and female codling moth Cydia pomonella (L.) Naturwissenschaften 88:333-338.

Mayer, D.G., and D.G. Butler. 1993. Statistical validation. Ecological Modeling 68:21-32.

Pickel, C.P., R.S. Bethell, and W.W. Coates. 1986. Codling moth management using degree days. Publication 4. University of California Statewide IPM Project, Berkeley, California, USA.

Pitcairn, M.J., F.G. Zalom, and W.J. Bentley. 1990. Weather factors influencing capture of Cydia pomonella (Lepidoptera: Tortricidae) in pheromone traps during overwintering flight in California Environmental Entomology 19:1253-1258.

Pitcairn, M.J., F.G. Zalom, and R.E. Rice. 1992. Degree-day forecasting of generation time of Cydia pomonella (Lepidoptera: Tortricidae) populations in California. Environmental Entomology 21:441-446.

Reyes, M., J. Bouvier, T. Boivin, C. Muñoz, E. Fuentes-Contreras, y B. Sauphanor. 2004. Susceptibilidad a insecticidas y actividad enzimática de Cydia pomonella L. (Lepidoptera: Tortricidae) provenientes de tres huertos de manzano de la Región del Maule, Chile. Agricultura Técnica (Chile) 64:229-237.

Riedl, H., B.A. Croft, and A.J. Howitt. 1976. Forecasting codling moth phenology based on pheromone trap catches and physiological-time models. Canadian Entomologist 108:449-460.

Samietz, J., B. Graf, H. Höhn, L. Schaub, and H. Höpli. 2007. Phenology modeling of major insect pests in fruit orchards from biological basics to decision support: the forecasting tool SOPRA. OEPP/EPPO Bulletin 37:255-260.

Tomkins, A., D. Penman, R. Chapman, and S. Worner. 1987. An evaluation of a phenological model (PETE) to assist insect pestcontrol in apple orchards in Canterbury. New Zealand Journal of Experimental Agriculture 15:381-388.

Varela, L.G., S.C. Welter, V.P. Jones, J.F. Brunner, and H. Riedl 1993. Monitoring and characterization of insecticide resistance in codling moth (Lepidoptera, Tortricidae) in four Western States. Journal of Economic Entomology 86:1-10.

Vial, C., L. Campos, L. Sazo, y J.A. Rustom. 1987. Fenología de Quadraspidiotus perniciosus (Comst.) en dos áreas frutícolas de Chile. 1. Validación del modelo predictivo (PETE) para adopción de decisiones de control. Simiente (Chile) 57:1-5.

Welch, S., B.A. Croft, J.F. Brunner, and M. Michels. 1978. PETE: An extension phenology modeling system for management of multispecies pest complex. Environmental Entomology 7:487-494.

Welch, S., B.A. Croft, and M. Michels. 1981. Validation of pest management models. Environmental Entomology 10:425-432. 